\title{
Ammonia treated Mo/AC catalysts for CO hydrogenation with improved oxygenates selectivity
}

\author{
SHARIF F ZAMAN*, NAGARAJU PASUPULETY*, ABDULRAHIM A AL-ZAHRANI, \\ MUHAMMAD A DAOUS, S S AL-SHAHRANI, HITOSHI INOKAWA, \\ LACHEZAR A PETROV and HAFEDH DRISS \\ Chemical and Materials Engineering Department, Faculty of Engineering, King Abdulaziz University, P.O. Box \\ 80204, Jeddah 21589, Saudi Arabia \\ E-mail: zfsharif@gmail.com; sfzaman@kau.edu.sa; pasupulety@gmail.com; nsampathrao@kau.edu.sa
}

MS received 25 December 2016; revised 21 March 2017; accepted 27 March 2017

\begin{abstract}
A series of ammonia treated Mo/Activated Carbon (AC) catalysts were synthesized by wet impregnation method by nominal incorporation of 5, 10 and $15 \mathrm{wt} \%$ of molybdenum. The calcined catalysts $\left(500^{\circ} \mathrm{C}, 4 \mathrm{~h}, \mathrm{~N}_{2}\right.$ flow) were subjected to a stepwise ammonia treatment at temperatures from 25 up to $700^{\circ} \mathrm{C}$. This work reports for the first time, ammonia treated different loadings of Mo on DARCO mesoporous activated carbon for $\mathrm{CO}$ hydrogenation reaction. These catalysts were tested in the reaction temperature range of 250 $325^{\circ} \mathrm{C}, 7 \mathrm{MPa}$ and $12000 / \mathrm{h}$ (GHSV for reactor volume $0.5 \mathrm{~mL}$ ). At $250^{\circ} \mathrm{C}$, all the catalysts showed total oxygenate selectivity of $\sim 50 \%$, mainly methanol. At $325^{\circ} \mathrm{C}$, total oxygenate selectivity of $16.5 \%$ with $18 \%$ $\mathrm{CO}$ conversion was obtained on 10Mo-N/AC. The result of alcohol distribution revealed high selectivity to propanol $(39 \%)$ over methanol $(34 \%)$ at $325^{\circ} \mathrm{C}$ on $10 \mathrm{Mo}-\mathrm{N} / \mathrm{AC}$ which highlights its unique catalytic behavior in $\mathrm{CO}$ hydrogenation. Further, $10 \mathrm{MoO}_{3} / \mathrm{AC}$ catalyst, with no treatment of ammonia, showed only $4 \%$ of $\mathrm{CO}$ conversion with $96 \%$ hydrocarbon selectivity. Only $0.5 \%$ of CO conversion was observed on $\mathrm{AC}$ itself at $325^{\circ} \mathrm{C}$. The improved oxygenates selectivity on $10 \mathrm{Mo}-\mathrm{N} / \mathrm{AC}$ was associated with $\mathrm{Mo}^{\delta+}$ sites on $\mathrm{AC}$ generated via ammonolysis.
\end{abstract}

Keywords. Molybdenum nitride; activated carbon; $\mathrm{CO}$ hydrogenation; liquid oxygenates; ammonolysis.

\section{Introduction}

One of the most important challenges that mankind will face in the upcoming years, is to secure the needed energy supply for the increasing energy demand, while at the same time minimizing the negative environmental impact of mass energy production. Syngas utilization is one of the interesting alternative routes for producing liquid fuels and a variety of chemicals. Syngas can be produced from different carbon containing materials, such as coal, natural gas and biomass by means of gasification and reforming. Syngas can be converted into hydrocarbons, methanol and higher alcohols depending on the type of catalyst used and reaction conditions.

Higher alcohol synthesis (HAS) is an exothermic process and low temperature and high pressure favor the alcohol formation. The side reactions taking place are water gas shift and formation of hydrocarbons. Synthesized hydrocarbons usually are dominated by methane together with certain amount of other high molecular weight paraffins and olefins. Non-alcoholic oxygenated

\footnotetext{
*For correspondence
}

products such as aldehydes, esters and ethers are also produced depending on the type of the catalyst used and operating conditions. ${ }^{1}$ A large number of published reports dealt with the preparation of oxygenates or hydrocarbons from syngas using bulk catalysts like $\mathrm{Ni}-\mathrm{Mo}_{2} \mathrm{~S},{ }^{1} \mathrm{Co}-\mathrm{Mo}_{2} \mathrm{~S},{ }^{2} \mathrm{Mo}_{2} \mathrm{C}^{3,4}$ and $\mathrm{MoP} .{ }^{1}$ Furthermore, $\mathrm{Cu}$ mixed $\mathrm{Co}$ catalysts were also extensively studied for HAS preparation from syngas. ${ }^{5}$

Supports like Activate Carbon (AC), $\mathrm{Al}_{2} \mathrm{O}_{3}, \mathrm{SiO}_{2}$ and $\mathrm{ZrO}_{2}$ have been studied for HAS by $\mathrm{CO}$ hydrogenation. The support effect strongly depends on the state of the active phase such as metal, oxide, and sulfide. Mo based catalysts with acidic supports such as $\mathrm{Al}_{2} \mathrm{O}_{3}$ and $\mathrm{ZrO}_{2}$ were found to suppress the alcohol formation pathways and increased the hydrocarbon formation during CO hydrogenation. ${ }^{6}$

Activated carbon as a support shows some potential advantages such as large surface area, high thermal stability and low tendency of carbon deposition. Spreading the Mo active phase on a high surface area support was found to be advantageous as it increases the number of active sites due to improved dispersion and distribution. ${ }^{7}$ 
Several studies were performed using activated carbon $^{8-10}$ and multi-walled carbon nanotubes (MWCNT), ${ }^{11,12}$ as supports for $\mathrm{MoS}_{2}$ that showed enhanced catalyst activity due to higher dispersion of the sulfide. K-promoted Ni-Mo catalysts supported on microporous activated carbon was used for syngas to HAS process by Liakaku et al. ${ }^{13}$ Ma et al. ${ }^{14}$ studied the influence of acid treated $\mathrm{AC}$ as a support with $\mathrm{K}-\mathrm{Ni}$ Mo active phase for $\mathrm{CO}$ hydrogenation reaction. The $\mathrm{K}-\mathrm{Ni}-\mathrm{Mo} / \mathrm{AC}$ catalyst was more selective to oxygenates ( $>40 \%, \mathrm{CO}_{2}$-free basis at $5 \mathrm{MPa}$ and $265^{\circ} \mathrm{C}$ ) over bulk $\mathrm{K}-\mathrm{Ni}$-Mo catalyst. The interaction of activated carbon with the Ni-Mo species prevents the complete reduction of the active metals $\left(\mathrm{Ni}^{0}\right.$ and $\mathrm{Mo}^{0}$ lead to methane formation) and preserves partially oxidized $\mathrm{Mo}$ and $\mathrm{Ni}$ species, which are thought to be active sites for alcohol formation. ${ }^{14}$ Zhang et al., ${ }^{15}$ synthesized Ni-Mo-K sulfide doped with $15 \%$ carbon nanotubes (CNT) and used for the syngas-to-HAS reaction. The authors concluded that CNT assists the hydrogen spillover to Ni-Mo-K surface and stabilizes the partially oxidized Ni-Mo species which led to higher alcohol formation.

Mesoporous AC, instead of microporous AC, have received much attention because of their relatively large pore size $(>2 \mathrm{~nm})$ and uniform porosity which facilitate the reactant diffusion, increases the pore accessibility and improves the dispersion of supported active component by confining them in the well-defined pores. ${ }^{16-18}$ Present work reports the first time, ammonia-treated different loadings of Mo on DARCO (trade mark for activated carbon derived from lignite and sold by ICI America, Inc., Wilmington, Delaware) mesoporous activated carbon (written as Mo-N/AC throughout this paper) for $\mathrm{CO}$ hydrogenation reaction. Further, the characteristics of the catalyst were established by BET-pore size distribution, $\mathrm{CO}$ and $\mathrm{H}_{2}$-TPD, XPS and HR-TEM techniques.

\section{Experimental}

\subsection{Materials}

Ammonium heptamolybdate $\left(\mathrm{NH}_{4}\right)_{6} \mathrm{Mo}_{7} \mathrm{O}_{24} \cdot 4 \mathrm{H}_{2} \mathrm{O}$ $(\geq 99.9 \%))$ and DARCO mesoporous activated carbon (AC) with 20-40 mesh grain size were purchased from SigmaAldrich. The obtained $\mathrm{AC}$ was dried at $100^{\circ} \mathrm{C}$ for $12 \mathrm{~h}$ and used without any further purification. According to the AC manufacturer, it contains $\leq 12 \%$ moisture, dust $\leq 0.4 \%$ and mineral impurities (K, Si, Sn and $\mathrm{Fe})<1 \%$.

\subsection{Catalyst preparation}

Ammonium heptamolybdate equivalent to 5, 10 and $15 \mathrm{wt} \%$ of Mo was dissolved in $50 \mathrm{~mL}$ of deionized water and the resulting solution was continuously stirred for $1 \mathrm{~h}$. To this solution, approximately $5 \mathrm{~g}$ of $\mathrm{AC}$ was added and the mixture was aged for $12 \mathrm{~h}$. The excess water was evaporated using a hot plate. The resulting solids were dried overnight in a preheated oven at $100^{\circ} \mathrm{C}$ under static air. All the prepared catalysts were calcined at $500^{\circ} \mathrm{C}$ for $4 \mathrm{~h}$ under $\mathrm{N}_{2}$ flow $(30 \mathrm{~mL} / \mathrm{min})$. The calcined samples were subjected to stepwise temperature programmed ammonia treatment. One gram of the calcined sample was placed in a quartz reactor fitted with quartz frit. The nitridation procedure was as follows: In the first step, catalyst was kept at $120^{\circ} \mathrm{C}$ for 30 min under continuous He flow. In the second step, gaseous ammonia was introduced to the catalyst bed with an approximate flow rate of $400 \mathrm{~mL} / \mathrm{min}$ and the reactor temperature was increased from 120 to $350^{\circ} \mathrm{C}$ with a ramping rate of $1{ }^{\circ} \mathrm{C} / \mathrm{min}$. In the third step, the catalyst temperature was increased from 350 to $700^{\circ} \mathrm{C}$ with a ramping rate of $0.5^{\circ} \mathrm{C} / \mathrm{min}$ and aged at this temperature for $2 \mathrm{~h}$ under continuous flow of ammonia. In the fourth step, the reactor was cooled down to room temperature under He flow at a rate of $30 \mathrm{~mL} / \mathrm{min}$. In the fifth step, the sample was passivated with $1 \mathrm{vol} . \% \mathrm{O}_{2}$-balanced $\mathrm{He}$ at a flow rate of $30 \mathrm{~mL} / \mathrm{min}$ for $1 \mathrm{~h}$.

These catalysts were denoted as 5Mo-N/AC, 10Mo-N/AC and $15 \mathrm{Mo}-\mathrm{N} / \mathrm{AC}$. Herein, the prefix 5, 10 and 15 represent the weight percentage of molybdenum impregnated on activated carbon. Until unless stated, these samples were used for characterization studies. The catalyst with no treatment of gaseous ammonia with $10 \mathrm{wt} \%$ Mo loading was denoted as $10 \mathrm{MoO}_{3} / \mathrm{AC}$.

\subsection{Catalyst characterization techniques}

The BET surface area and pore size distribution of the samples used in the present study were determined by a Quantachrome Nova Station adsorption equipment at liquid nitrogen temperature after outgassing the samples at $200^{\circ} \mathrm{C}$ under the flow of $\mathrm{N}_{2}$ for $2 \mathrm{~h}$.

The X-ray diffractograms of the samples used in the present study were obtained on a EQUINOX 1000 inel XRD instrument using $\mathrm{Co} \mathrm{K}_{\alpha}=1.7902 \AA$, X-ray source generator settings at $40 \mathrm{kV}$ and $30 \mathrm{~mA}$ with real time acquisition over $110^{\circ}$ of $2 \theta$. The FTIR analysis of Mo-N/AC samples was performed on a Bruker Vertex 70/70v FTIR spectrometer using $\mathrm{KBr}$ pellet method. Transmission electron microscopy (TEM) images and high resolution TEM images and energy dispersive X-ray analysis (EDS) of Mo-N/AC samples were collected on Technai 200 kV D1234 Super Twin microscope with camera length of $97 \mathrm{~cm}$.

XPS results of Mo-N/AC samples were collected on a SPECS GmbH high vacuum multi-technique surface analysis system equipped with $\mathrm{Mg} \mathrm{K} \propto 1253.6 \mathrm{eV}$ X-ray source. Temperature programmed desorption (TPD) analysis of Mo-N/AC samples were determined using adsorption-desorption of $\mathrm{CO}$ and $\mathrm{H}_{2}$ with Quantachrome pulsar automated chemisorption instrument. All gases were supplied by Abdulla Hashim Gas (AHG), Saudi Arabia, and certified concentration (14.95\% $\mathrm{CO}-\mathrm{He}$ and $99.99 \% \mathrm{H}_{2}$ ) was used as a probe gas. In a typical 
experiment, approximately $0.1 \mathrm{~g}$ of catalyst was pretreated in He gas flow $(10 \mathrm{~mL} / \mathrm{min})$ at $200^{\circ} \mathrm{C}$ for $1 \mathrm{~h}$ followed by hydrogen treatment at $400^{\circ} \mathrm{C}$ for $4 \mathrm{~h}$. Subsequently, the catalyst was brought to room temperature under the flow of He and saturated with probe gas (either $\mathrm{CO}$ or $\mathrm{H}_{2}$ ). Desorption of probe gas was performed after $1 \mathrm{~h}$ of He flushing over a temperature range of $30-400^{\circ} \mathrm{C}$ at a ramping rate of $10^{\circ} \mathrm{C} / \mathrm{min}$.

\subsection{Catalytic activity tests}

Catalytic activity tests were performed using PID Eng and Tech system (Spain) equipped with a flow microreactor, mass flow, pressure and temperature controllers. The mixture of $\mathrm{CO}: \mathrm{H}_{2}=1: 1$ volume ratio was selected as model feed at $12000 / \mathrm{h}$ (reactor volume $0.5 \mathrm{~mL}$ ) GHSV (gas hourly space velocity). Catalytic activity tests were carried out in the temperature range of $250-325^{\circ} \mathrm{C}$ with $25^{\circ} \mathrm{C}$ step size at the applied pressure of $7 \mathrm{MPa}$. All the gases for the catalytic activity tests were supplied by Abdulla Hashim Gas (AHG), Saudi Arabia.

For example, $500 \mathrm{mg}$ of Mo-N/AC catalyst was loaded in to a copper lined stainless steel tube reactor (inside diameter $6.35 \mathrm{~mm}$ and length $9.53 \mathrm{~mm}$ ) diluted with equal amount of quartz beads was treated with $\mathrm{H}_{2}$ flow of $50 \mathrm{~mL} / \mathrm{min}$ at $500^{\circ} \mathrm{C}$ for $2 \mathrm{~h}$. Subsequently, the $\mathrm{H}_{2}$ flow was replaced by $\mathrm{N}_{2}$ and reactor temperature was brought back to $250^{\circ} \mathrm{C}$. The reactant gas mixture $\mathrm{CO}: \mathrm{H}_{2}=1: 1$ volume ratio was introduced with flow rate of $100 \mathrm{~mL} / \mathrm{min}$ through an activated carbon trap (which traps iron carbonyls formed inside the gas tank) into the reactor to attain the required pressure. After attaining the steady state at a set temperature and pressure of the reaction, the reactor exit stream was directed through a heated line at $160^{\circ} \mathrm{C}$ to Agilent $7890 \mathrm{~A}$ GC equipped with TCD connected with Restek Plot Q column for $\mathrm{CO}$ and $\mathrm{CO}_{2}$ separation and to flame ionization detector (FID) fitted with HP Plot Q column for separation of hydrocarbons (methane, ethane, ethylene, propane, propylene and butane) and oxygenates (methanol, ethanol, propanol, butanol, acetone, acetic acid, acetaldehyde and ethyl acetate) estimation. Acetone, acetic acid, acetaldehyde and ethyl acetate are reported as other oxygenates in the activity results. At each temperature, five experimental points were collected and the results were reproducible within the error of $\pm 0.1 \%$. The same catalyst load was used for the tests at the three reaction temperatures. Negligible $(<0.1 \%)$ $\mathrm{CO}$ conversion was found on empty SS copper lined reactor under identical reaction conditions. The syngas conversion and selectivity of the products were calculated by the following equations:

$$
\begin{aligned}
& \text { CO conversion (mass \%) } \\
& =\frac{\text { CO initial moles }- \text { CO final moles }}{\text { CO initial moles }} \times 100 \\
& \text { Selectivity }(\text { mass } \%)=\frac{n_{i} C_{i} \text { prodcut }}{\sum n_{i} C_{i}} \times 100
\end{aligned}
$$

where, $n_{i}$ is the number the carbon atoms in the molecule of the ith component and $\mathrm{C}_{\mathrm{i}}$ is the mole fraction of ith component in the reaction mixture at the reactor exit.

\section{Results and Discussion}

\subsection{BET surface area and pore size distribution studies}

Figure 1a shows the physorption isotherms of activated carbon $(\mathrm{AC})$ and Mo-N/AC samples. The AC and Mo-N/AC exhibited type-II Brunauer-Deming-DemingTeller isotherms typical for mesoporous solids. ${ }^{19}$ Adsorption hysteresis was reported due to multilayer physorption isotherms usually associated with capillary condensation in mesopores. In the present study, $\mathrm{H} 4$ type hysteresis loops were observed, which were associated with narrow slit-like pores in all the samples. ${ }^{20}$ Furthermore, in Mo-N/AC samples, capillary condensation of adsorbate $\mathrm{N}_{2}$ in the pores occurred at a lower relative pressure than that of AC under similar physorption conditions (catalyst $200 \mathrm{mg}$ and $200^{\circ} \mathrm{C}, 2 \mathrm{~h}, \mathrm{~N}_{2}$ pretreatment), which is indicative of reduction in the pore size of AC in Mo-N/AC samples. This might be
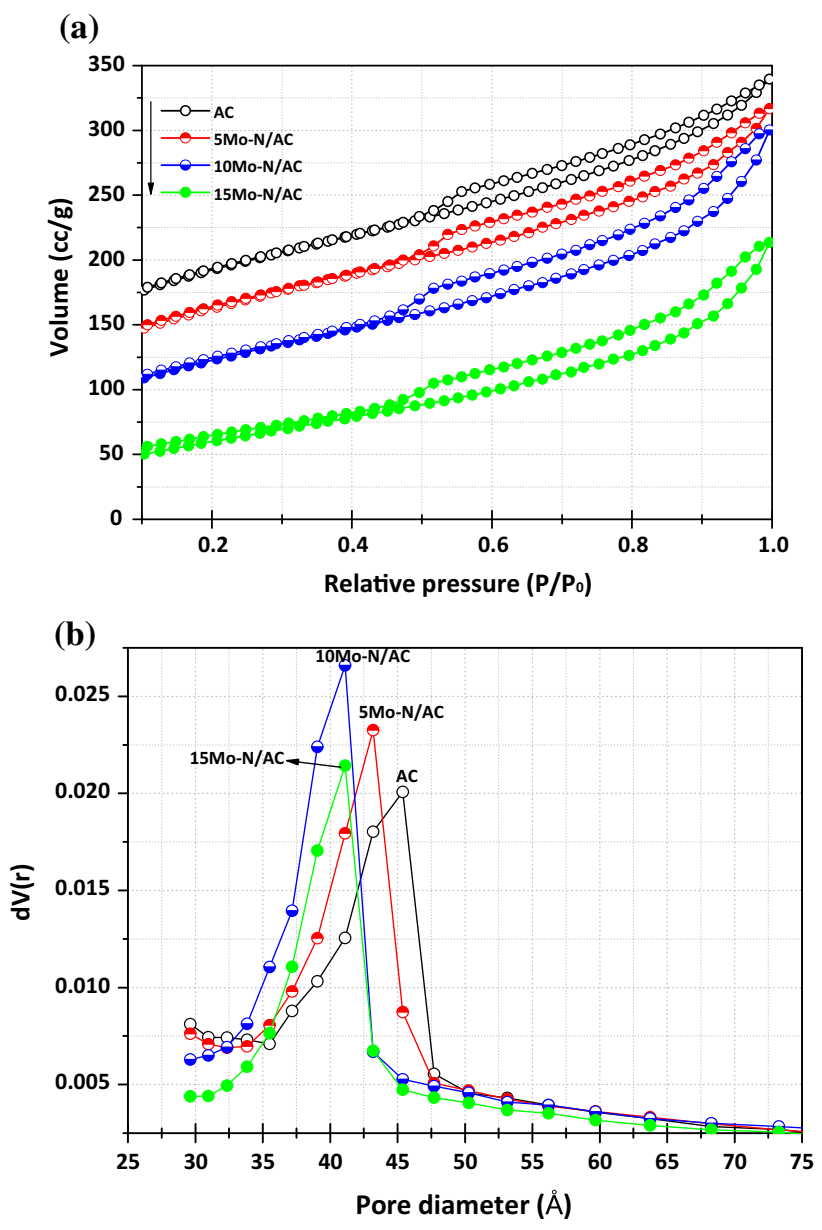

Figure 1. (a) BET isotherms; (b) pore size distribution in terms of derivative expression of pore volume with pore size between $\mathrm{r}$ and $\mathrm{r}+\mathrm{dr}$ for samples AC and Mo-N/AC. 
associated with the location of Mo in the mesopores of AC with Mo loadings.

Figure $1 \mathrm{~b}$ presents the $\mathrm{BJH}$ pore size distribution of $\mathrm{AC}$ and Mo-N/AC samples. Unimodal mesopore distribution was observed in all these samples with the pore diameter range of $30-50 \AA$. The AC showed mesoporous texture in the range of $35-50 \AA$ and averaged at $45 \AA$. On the other hand, Mo-N/AC samples showed a shift in the mesopore average diameter to lower side (Figure 1a hysteresis loop was shifted to lower $\mathrm{P} / \mathrm{P}_{0}$ ). For instance, 5Mo-N/AC showed mesopores in the range of 34-47.5 $\AA$ and averaged at $43 \AA$ and 10- and $15 \mathrm{Mo}-\mathrm{N} / \mathrm{AC}$ samples showed mesopores in the range of 32-45.0 $\AA$ and averaged at $41.0 \AA$. The results indicate that the mesopores distribution in a wide range in support $\mathrm{AC}$, whereas, partial filling of $\mathrm{AC}$ pores by Mo component narrowed the diameter range of mespores in Mo-N/AC samples. Further, at $15 \mathrm{wt} . \%$ of Mo loading, AC showed reduced volume of mesopores compared to 10Mo-N/AC sample which suggests, to some extent, that mesopores were filled totally by Mo species at this loading of Mo (Figure 1b, line with filled circle). Champson et al. ${ }^{21}$ also reported reduction of BET surface area and pore volume for temperature programmed ammonia treated 10Mo-N/AC (DARCO) catalyst over its support. The authors related that the reduction of pore volume and BET surface area was due to Mo-N formation inside the mesopores of AC. In this study, the systematic transformation of mesopore diameter to narrow size upon Mo loading on AC was associated with stepwise temperature programmed ammonia treatment, which resulted in the formation of Mo-N species in the mesopores of AC.

The AC showed the BET surface area and mesopore volume as $609.0 \mathrm{~m}^{2} / \mathrm{g}$ and $0.460 \mathrm{~mL} / \mathrm{g}$,respectively. On the other hand, the BET surface area and mesopore volume for 5-, 10- and $15 \mathrm{Mo}-\mathrm{N} / \mathrm{AC}$ samples obtained as $561.0,486.0$ and $218 \mathrm{~m}^{2} / \mathrm{g}$ and $0.449,0.420$ and $0.297 \mathrm{~mL} / \mathrm{g}$, respectively. The decrease in the volume of mesopores was associated with partial filling of AC mesopores with Mo-N species. Despite the pore filling, the integrity of mesopore structure of AC in Mo-N/AC was intact, as observed by the $\mathrm{N}_{2}$ sorption isotherms.

\subsection{XRD analysis}

XRD spectra of AC and Mo-N/AC samples are presented in Figure $\mathrm{S} 1$ (Supplementary Information). Support (AC) related $\mathrm{X}$-ray reflections are pronounced at $2 \theta=22.0,24.0,31.2,42.8,44.5,46.25,49.9,52.0$, $59.0,71.0,76.0,81.0$ and $98.0^{\circ}$ which are attributed to activated carbon graphene framework. Identical reflections were pronounced at similar $2 \theta$ values due to the support in Mo-N/AC samples. No XRD reflections were observed for Mo phases up to $15 \mathrm{wt} \%$ of Mo loading on AC. No crystalline phases of molybdenum were detected for $10 \mathrm{wt} \%$ of Mo on Norit activated carbon catalysts and attributed to a high degree of dispersion of the Mo phase on the support. ${ }^{22}$ However, in the present study, the intensity of the AC related X-ray reflections were decreased for samples from 5Mo-N/AC to $15 \mathrm{Mo}-$ N/AC under identical XRD conditions (30 mg catalyst, $2 \mathrm{~h}$ analysis). This phenomenon was likely due to interactions of Mo species with activated carbon graphite structure. The results suggest that the Mo-related crystallites are $\leq 4 \mathrm{~nm}$, and/or distributed well on the surface of the support.

\subsection{FTIR studies}

FTIR studies were performed to determine the changes on the surface carbon-oxygen functional groups with Mo loading in Mo-N/AC samples and the results are presented in Figure S2 (Supplementary Information). The FTIR spectra of AC exhibited major bands in the fingerprint region (400-1500 $\mathrm{cm}^{-1}$ ) and minor bands in the functional group region $\left(4000-1500 \mathrm{~cm}^{-1}\right)$. The broad band in the region of $950-1300 \mathrm{~cm}^{-1}$ (centered at $1100 \mathrm{~cm}^{-1}$ ) is ascribed to $\mathrm{C}-\mathrm{O}$ stretching vibration, such as those in ethers, phenols and hydroxyl groups. ${ }^{23}$ The weak bands observed at 700 and 780 $800 \mathrm{~cm}^{-1}$ are attributed to out-of-plane $\mathrm{O}-\mathrm{H}$ bending and out-of-plane $=\mathrm{C}-\mathrm{H}$ bending vibrations, respectively. The presence of $1580 \mathrm{~cm}^{-1}$ stretching vibration reveals the carbonyl functional groups $(\mathrm{C}=\mathrm{O})$ on $\mathrm{AC}$. The band appearing around $3400 \mathrm{~cm}^{-1}$ is ascribed to O-H stretching vibration of carboxylic acid or physically adsorbed water. Similar bands are pronounced in the region of 950-1300 and 700-800 $\mathrm{cm}^{-1}$ for Mo-N/AC samples, which indicate the intact $\mathrm{AC}$ surface functional groups even after Mo impregnation and ammonolysis process. In addition, new bands appeared at 900, 1400 and $3100 \mathrm{~cm}^{-1}$ in Mo-N/AC samples. The bands at 900 and $3100 \mathrm{~cm}^{-1}$ are ascribed to $\mathrm{C}-\mathrm{H}$ vibrations in aromatic carbon structures. ${ }^{23}$ The appearance of these bands after the impregnation of Mo on AC might be associated with the formation of C-H bonds in aromatic rings, as a consequence of the opening of cyclic ether bridges by the interaction of molybdenum species with ether groups ${ }^{23}$ or hydrogenation of $s p^{2}$ carbon during the ammonolysis process. The band at $1400 \mathrm{~cm}^{-1}$ is related to deformational vibration of physically adsorbed water. ${ }^{24}$

The decrease in the infrared intensity of carboxyl or conjugated carbonyl groups at $1720 \mathrm{~cm}^{-1}$ in $15 \mathrm{Mo}-$ N/AC was related to the interaction between molybdenum species with carboxyl or conjugated carbonyl 
groups. ${ }^{25}$ In the present study, more prominent C-O vibration was observed on $\mathrm{AC}$ at $1100 \mathrm{~cm}^{-1}$. However, the intensity of this band was relatively decreased with increase of the Mo loading in Mo-N/AC samples. The result suggests $\mathrm{C}-\mathrm{O}$ groups are chemical anchoring centers for the studied Mo-N/AC samples which led to Mo-O-C type of complexes in agreement with XPS data where $\mathrm{C}-\mathrm{O}$ signal was grown with increasing of the Mo loading.

\subsection{XPS measurements}

Figure S3 (Supplementary Information) presents C $1 s$, $\mathrm{O} 1 s$ and Mo $3 d$ XPS patterns for AC and Mo-N/AC samples. The AC itself showed broad pattern for $\mathrm{C} 1 s$ and the satellite bands in the binding energy range of 282.0-293.0 eV are attributed to different types of oxygen containing functional groups on AC surface. The Shirley deconvolution of $\mathrm{C} 1 s$ yielded six chemicallyshifted signals as shown in Figure $\mathrm{S} 3$. The $\mathrm{C} 1 s$ peak centered at $284.6 \mathrm{eV}$ is ascribed to $s p^{3}$ carbon of $\mathrm{AC}$ as the major component. The peak at relatively lower binding energy $(283.7 \mathrm{eV})$ is endorsed to $\mathrm{C}=\mathrm{C}\left(s p^{2}\right.$ carbon) which suggests the presence of unoxidized domains in AC. Additionally, four more carbon-related components exist at 285.5, 287.0, 289.5 and $291.0 \mathrm{eV}$. They are assigned to $-\mathrm{C}-\mathrm{O}$, carbonyl $(-\mathrm{C}=\mathrm{O})$, carboxylate $\left({ }^{-} \mathrm{O}-\mathrm{C}=\mathrm{O}\right)$ and carboxyl $(-\mathrm{COOH})$ functionalities, respectively. ${ }^{26}$ Identical components, pronounced due to $\mathrm{C} 1 s$ in Mo-N/AC samples (Figure S3), indicate that all characteristic functional groups of $\mathrm{C} 1 \mathrm{~s}$ remained intact, even after Mo was impregnated on AC. However, the changes observed in Mo-N/AC samples with respect to Mo loading are as follows: (i) The intensity of C-C peak was reduced and a prominent XPS tail (around 285.5 $\mathrm{eV}$ ) appeared from AC to $15 \mathrm{Mo}-\mathrm{N} / \mathrm{AC}$ which indicates possible interactions exist between surface Mo and AC functional groups. (ii) In particular, relatively intensified $-\mathrm{C}-\mathrm{O}$ and $-\mathrm{C}=\mathrm{O}$ bands with respect to Mo loading indicates the presence of the interaction between the surface Mo atoms and these functional groups through delocalization of electrons.

O $1 s$ XPS pattern of AC and Mo-N/AC samples are presented in Figure S3. The Shirley deconvolution of $\mathrm{O} 1 s$ yields four different components in the binding energy range of 528-540 eV. The peak centered at $532.8 \mathrm{eV}$ is attributed to carbonyl oxygen $(\mathrm{C}=\mathrm{O})$. The peaks registered at 534.0 and $535.2 \mathrm{eV}$ are ascribed to hydroxyl oxygen $(\mathrm{C}-\mathrm{OH})$ and carboxylate/carboxyl oxygen, respectively. ${ }^{19}$ The peak centered at $530.8 \mathrm{eV}$ suggests the presence of lattice oxygen in O-Mo species.

Furthermore, Figure S4 (Supplementary Information) shows that the Mo $3 d$ peaks are pronounced at 232.6 and
$235.7 \mathrm{eV}$ due to the split components of $3 d_{5 / 2}$ and $3 d_{3 / 2}$, respectively. The existence of these bands suggests that the $\mathrm{Mo}^{6+}$ valence state is present in all the studied catalysts. ${ }^{21}$ The surface molybdenum content (atomic \%) on $5 \mathrm{Mo}-\mathrm{N} / \mathrm{AC}, 10 \mathrm{Mo}-\mathrm{N} / \mathrm{AC}$ and $15 \mathrm{Mo}-\mathrm{N} / \mathrm{AC}$ was found to be $0.40,0.70$ and 0.82 atomic percentage, respectively.

3.4a CO-TPD studies: CO-TPD results of reduced $\mathrm{AC}$ and Mo-N/AC samples are presented in Figure 2a. No CO sorption was observed on AC. On the other hand, a single desorption signal was observed in all the studied $\mathrm{Mo} / \mathrm{AC}$ samples. On 5- and 15Mo-N/AC, CO desorption peak maximum was observed at $165^{\circ} \mathrm{C}$ with a capacity of 45 and $50 \mu \mathrm{mol} / \mathrm{g}$, respectively. However, for $10 \mathrm{Mo}-$ N/AC, CO desorption peak maximum was observed at $200^{\circ} \mathrm{C}$ with a capacity of $100 \mu \mathrm{mol} / \mathrm{g}$. These results indicate that $\mathrm{CO}$ sorption is relatively higher at $10 \mathrm{wt} \%$ of Mo loading over 5 and $15 \mathrm{wt} \%$. This is associated with homogeneous distribution of Mo species at this loading on AC, as observed by TEM analysis. Three types of $\mathrm{CO}$ sorptions were reported on $\mathrm{Mo} / \mathrm{Al}_{2} \mathrm{O}_{3}$ surface: ${ }^{27}$ (i) physically adsorbed $\mathrm{CO}$ in the temperature range of $25-80^{\circ} \mathrm{C}$; (ii) molecular $\mathrm{CO}$ adsorption in the temperature range of $100-300^{\circ} \mathrm{C}$; and (iii) dissociative $\mathrm{CO}$ adsorption in the temperature range of $600-1000^{\circ} \mathrm{C}^{28}$. Bulk $\mathrm{Mo}_{2} \mathrm{~N}$ displayed two $\mathrm{CO}$ desorption peaks at 165 and $300^{\circ} \mathrm{C}$. The first $\mathrm{CO}$ desorption peak was assigned to desorption of molecularly adsorbed $\mathrm{CO}$ on $\mathrm{Mo}^{\delta+}\left(\mathrm{Mo}^{2+}\right.$ and $\mathrm{Mo}^{3+}$ ) sites $(\mathrm{Mo}-\mathrm{C} \equiv \mathrm{O})$. The later $\mathrm{CO}$ desorption peak was assigned to desorption of NCO species. ${ }^{29}$ In this study, all the Mo-N/AC samples displayed molecular $\mathrm{CO}$ desorption peaks with maxima in the range of $150-200^{\circ} \mathrm{C}$ with different $\mathrm{CO}$ desorption capacities. According to Miura et al. ${ }^{28}$ molecular CO desorption can be enhanced by the surface modification of Mo species. The CO-TPD result reveals $\mathrm{CO}$ sorption on $\mathrm{Mo}^{+\delta}$ sites present on $\mathrm{AC}$ in Mo-N/AC samples.

3.4b $\quad H_{2}$-TPD studies: $\mathrm{H}_{2}$-TPD results of Mo-N/AC samples are presented in Figure 2b. A single desorption signal characterized by several humps were observed in the temperature range of $150-350^{\circ} \mathrm{C}$ in all MoN/AC samples. Hydrogen desorption from Mo (100) surface was reported to happen at room temperature. ${ }^{27}$ It was accepted that the hump-like profile was the result from either reversible adsorption of $\mathrm{H}_{2}$ and/or simultaneous $\mathrm{H}_{2}$ desorption from the $\mathrm{Mo} / \mathrm{AC}$ surface. The maximum $\mathrm{H}_{2}$ desorption of $60 \mu \mathrm{mol} / \mathrm{g}$ was observed at $10 \mathrm{Mo}-\mathrm{N} / \mathrm{AC}$ compared to $5-$ and $15 \mathrm{Mo}-\mathrm{N} / \mathrm{AC}$ samples. Hence, the decreasing order of $\mathrm{H}_{2}$ desorption is as follows: $10 \mathrm{Mo}-\mathrm{N} / \mathrm{AC}(60 \mu \mathrm{mol} / \mathrm{g})>15 \mathrm{Mo}-\mathrm{N} / \mathrm{AC}$ $(26 \mu \mathrm{mol} / \mathrm{g})>5 \mathrm{Mo}-\mathrm{N} / \mathrm{AC}(17 \mu \mathrm{mol} / \mathrm{g})$. The result 
(a)

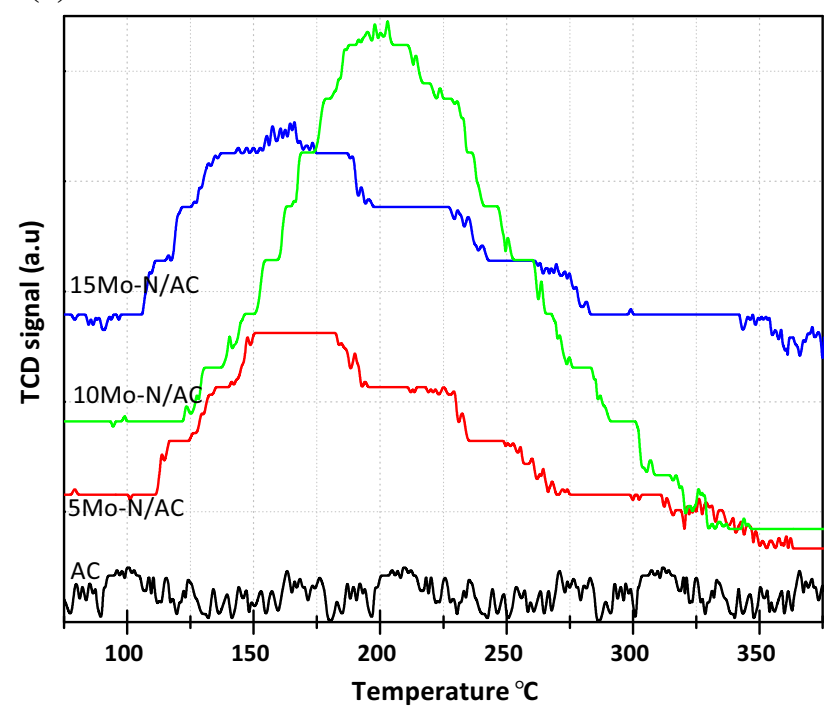

(b)

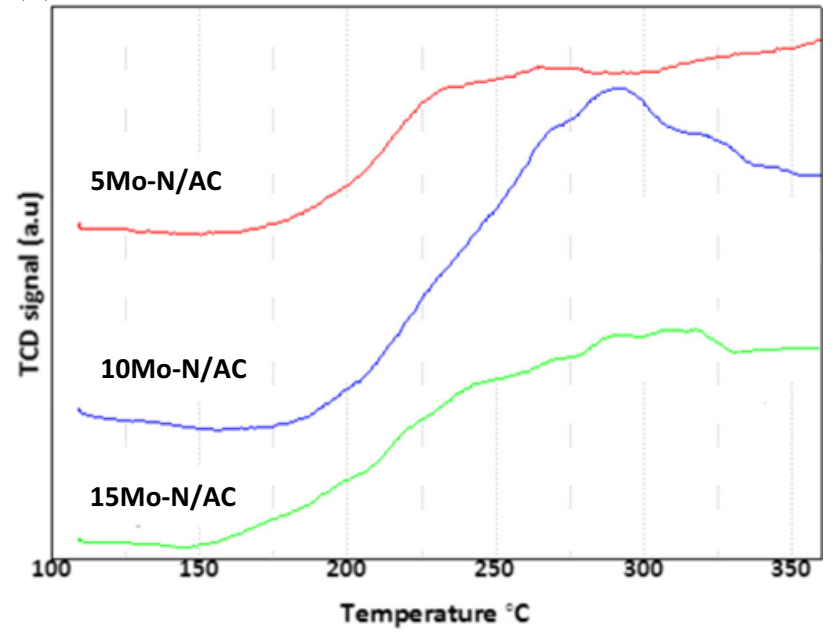

Figure 2. (a) CO-TPD results of AC and Mo-N/AC samples in terms of thermal conductivity signal (a. u.). (b) $\mathrm{H}_{2}$-TPD results.

indicates that the $\mathrm{CO}$ was preferentially adsorbed on Mo species rather than hydrogen.

\subsection{TEM studies}

The TEM images of AC and Mo-N/AC samples are presented in Figure S5 (Supplementary Information). The wrinkle-folded morphology was observed for AC (Figure $\mathrm{S5}(\mathrm{a})$ ), which is attributed to the carbon in $s p^{3}$ hybridization in $\mathrm{C}-\mathrm{C}$ and or $\mathrm{C}-\mathrm{O}$ links. ${ }^{30}$ The morphology of the carbon changed upon Mo loading and appears as nebulous type. The Mo spherical particles (marked with circle) are distributed on the $\mathrm{AC}$ with the size range of $1-3 \mathrm{~nm}$. The large sized $(\approx 4 \mathrm{~nm})$ Mo particles on $\mathrm{AC}$ were observed at $15 \%$ loading (Figure S5(d)) which suggest aggregation of Mo particles. Usually, Mo species agglomerate because of the elec- trostatic attractions between anionic part of one unit and counter cationic part of the other unit. ${ }^{30}$ Mo content by EDS analysis for 5-, 10- and $15 \mathrm{Mo-N} / \mathrm{AC}$ samples were found to be 4.8, 9.5 and $14.0 \mathrm{wt} \%$, respectively, which agree with the nominal loading of the Mo metal at the impregnation step.

The high resolution TEM images of 10Mo-N/AC sample are presented in Figure S6 (Supplementary Information). Well-distributed Mo particles (marked with circles in Figure S6(a)) are observed in the wrinkled channels of AC. The Mo particles are sized in the range of 1-2 $\mathrm{nm}$. The d-spacing line profile of Mo particle is presented in Figure S6 (b). The d-spacing of channels $(0.144 \mathrm{~nm})$ is consistent with the plane (062) of orthorhombic molybdenum trioxide [00-005-0508]. These results are in agreement with XPS data where $\mathrm{Mo}^{6+}$ valence state is observed.

In present work, ammonia treated sample characterization exhibited oxide form of Mo. This might be associated with quick conversion of nanosized Mo-N particles $(\leq 4 \mathrm{~nm})$ to oxide under X-ray or electron beam exposure and or due to catalyst exposure to atmospheric air during the characterization. For this reason, we performed the catalytic activity test on ammoniagas-untreated $\mathrm{MoO}_{3} / \mathrm{AC}$ catalyst for this reaction. In the following section, activity results reveal that the catalytic behavior of Mo-N/AC is different in fair amount, in both conversion and selectivity, when compared with those of $\mathrm{MoO}_{3} / \mathrm{AC}$ catalyst.

\subsection{Catalytic activity}

The CO hydrogenation activity results on the prepared catalysts are presented in Figure 3. The catalytic activity tests were performed in the temperature range of $250-325^{\circ} \mathrm{C}, 7.0 \mathrm{MPa}$ and $12000 / \mathrm{h}$ GHSV (reactor volume $0.5 \mathrm{~mL}$ ). Catalytic activity of the support was also studied under similar reaction conditions. Only, $<0.5 \% \mathrm{CO}$ conversion was observed on $\mathrm{AC}$ at $325^{\circ} \mathrm{C}$. On the other hand, maximum CO conversion of $18.0 \%$ was observed on $10 \mathrm{Mo}-\mathrm{N} / \mathrm{AC}$ compared to $5 \mathrm{Mo}-\mathrm{N} / \mathrm{AC}$ $(9.5 \%)$ and $15 \mathrm{Mo}-\mathrm{N} / \mathrm{AC}(13.5 \%)$ at $325^{\circ} \mathrm{C}$. The result suggests inadequate amount of Mo active surface at $5 \%$ Mo loaded sample, and at $15 \%$ Mo loading, aggregation of Mo species leads to low catalytic activity. Hence, $10 \%$ Mo loading was found to be optimal for AC for $\mathrm{CO}$ hydrogenation reaction. Further, $\mathrm{CO}$ conversion was increased with an increase in the reaction temperature. Hydrocarbon selectivity was increased with an increase in the reaction temperature for all the Mo-N/AC catalysts. Higher temperature is favorable for the formation of hydrocarbons and $\mathrm{CO}_{2}$ via water gas shift reaction. The higher hydrocarbon formation can also be 

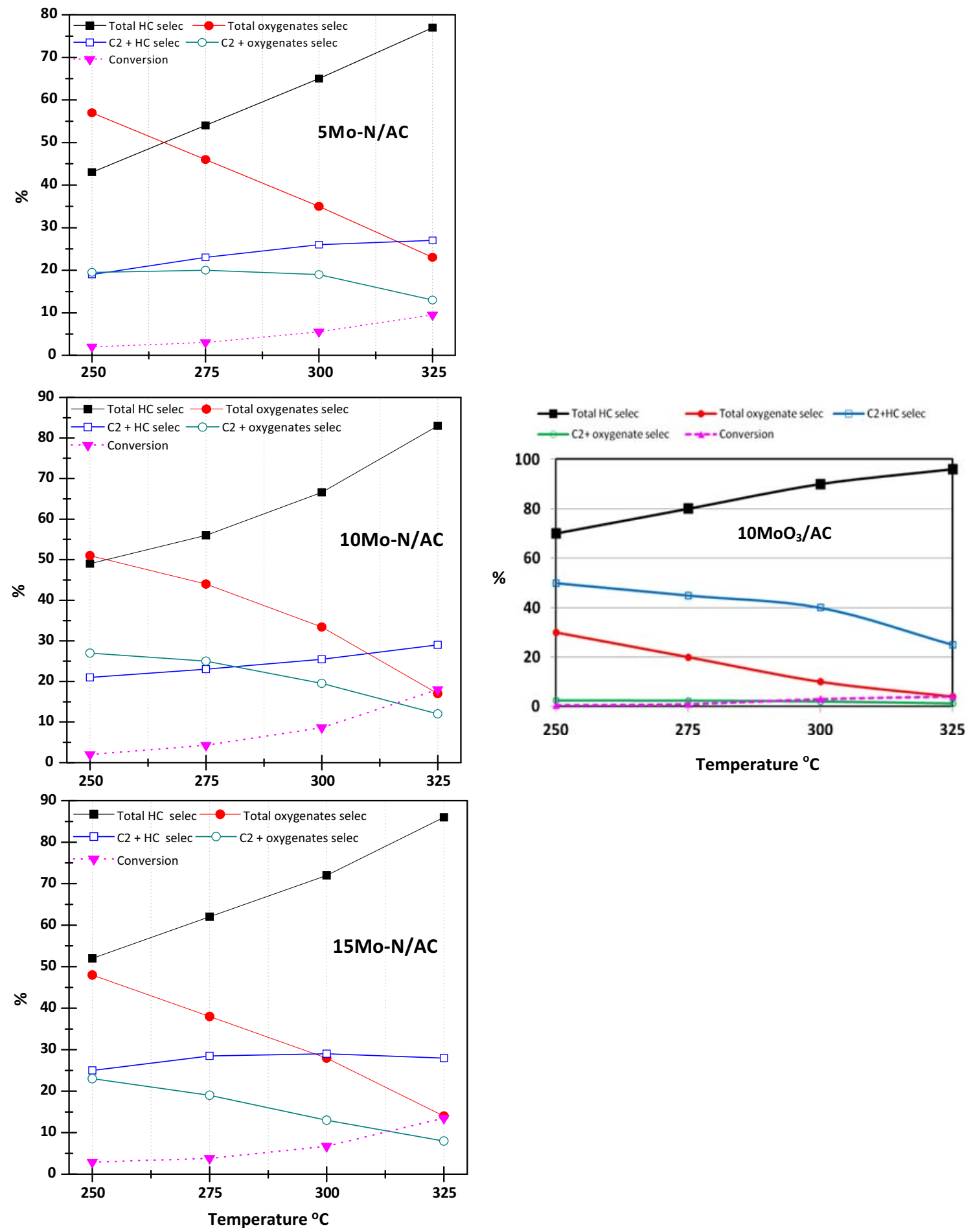

Figure 3. $\mathrm{CO}$ hydrogenation activity on $\mathrm{Mo} / \mathrm{AC}$ catalysts at reaction temperature $250-325^{\circ} \mathrm{C}, 7 \mathrm{MPa}$ and GHSV $12000 / \mathrm{h}$ (reactor volume $0.5 \mathrm{~mL}$ ).

related to the hydrogenation of carbonaceous intermediates $\left(-\mathrm{C}_{\mathrm{x}} \mathrm{H}_{\mathrm{Y}}\right)$ rather $\mathrm{CO}$ insertion into it. ${ }^{29}$ Furthermore, the increased $\mathrm{CO}_{2}$ concentration at higher temperatures can also alter the $\mathrm{CO} / \mathrm{H}_{2}$ ratio in the reactor zone and influence the $\mathrm{CO}$ insertion process followed by higher alcohol formation. In the present work, increased hydrocarbon selectivity with increased CO conversion with respect to reaction temperature suggests higher hydrogenation tendency of these catalysts.

On the other hand, the total oxygenates selectivity decreased with increase in the reaction temperature. The studied Mo-N/AC catalysts showed maximum oxygenates selectivity, $\sim 50 \%, \mathrm{CO}_{2}$-free basis, mainly methanol in the liquid product, at $250^{\circ} \mathrm{C}$, however, with 
a low $\mathrm{CO}$ conversion $(\sim 2.0 \%)$. At $300^{\circ} \mathrm{C}$, a reasonable $\mathrm{CO}$ conversion of $5.5,8.6$ and $6.7 \%$, with a reasonable total oxygenate selectivity of 30,35 and $28 \%$ were observed on 5-, 10- and 15 Mo-N/AC catalysts, respectively.

Catalysts, respectively. Further, oxygenates selectivity of $21 \%$ with $9.5 \%$ CO conversion was obtained on 5Mo-N/AC, whereas, around $14 \%$ of both oxygenates selectivity and $\mathrm{CO}$ conversion was observed on $15 \mathrm{Mo}-$ $\mathrm{N} / \mathrm{AC}$ at $325^{\circ} \mathrm{C}$. Around $16.5 \%$ of total oxygenates selectivity with $18 \% \mathrm{CO}$ conversion was obtained on $10 \mathrm{Mo}-\mathrm{N} / \mathrm{AC}$ at $325^{\circ} \mathrm{C}$. Decrease in oxygenate selectivity was compensated by the increase in hydrocarbons, especially methane. Also $\mathrm{C}_{2}^{+}$hydrocarbon selectivity increased with reaction temperature suggesting an increase in hydrogenation capacity of Mo-N/AC catalyst at higher temperatures, i.e., hydrogenation of liquid oxygenates to produce the corresponding hydrocarbons.

The catalytic activity of $10 \mathrm{MoO}_{3} / \mathrm{AC}$ (without ammonia treated catalyst) was also studied under similar reaction conditions and the results are compared with $10 \mathrm{Mo}-\mathrm{N} / \mathrm{AC}$ catalyst. Only $4 \%$ of CO conversion, with $96 \%$ hydrocarbon and $4 \%$ oxygenate selectivity, was observed on $10 \mathrm{MoO}_{3} / \mathrm{AC}$ at $325^{\circ} \mathrm{C}$. The $10 \mathrm{MoO}_{3} / \mathrm{AC}$ catalyst has exhibited considerable amount of methanol with very little amounts of ethanol, propanol and other oxygenates in the liquid product distribution. On the other hand, oxygenates selectivity was significantly improved to $16.5 \%$ on $10 \mathrm{Mo}-\mathrm{N} / \mathrm{AC}$ catalyst at $325^{\circ} \mathrm{C}$. However, on $10 \mathrm{MoO}_{3} / \mathrm{AC}$ catalyst also at lower reaction temperature $\left(250^{\circ} \mathrm{C}\right)$, maximum oxygenates selectivity of $30 \%$ with $0.5 \% \mathrm{CO}$ conversion was observed. These results suggest that improved oxygenates selectivity due to ammonia treatment might be associated with $\mathrm{Mo}^{\delta+}$ sites of Mo-N/AC catalysts. The results are in agreement with our CO-TPD data where, molecular $\mathrm{CO}$ adsorption take place on $\mathrm{Mo}^{\delta+}$ sites.

Li et al. ${ }^{31}$ reported 36\% CO conversion with $99 \%$ hydrocarbon selectivity on $18 \mathrm{Mo} / \mathrm{AC}$ (not treated with gaseous form of ammonia) catalyst at $325^{\circ} \mathrm{C}, 5 \mathrm{MPa}$ and GHSV $6 \mathrm{~m}^{3} / \mathrm{h} / \mathrm{kg}$. Hydrocarbon formation, particularly methane formation, in CO hydrogenation using Mo based catalysts was reported in the following order: Mo metal $\left(\mathrm{Mo}^{0}\right)>\mathrm{Mo}_{2} \mathrm{~N}\left(\mathrm{Mo}^{\delta+}\right)>\mathrm{MoO}_{2}\left(\mathrm{Mo}^{4+}\right)>$ $\mathrm{MoO}_{3}\left(\mathrm{Mo}^{6+}\right){ }^{32}$ The decrease in the $\mathrm{CO}$ conversion on $10 \mathrm{MoO}_{3} / \mathrm{AC}$ catalyst is associated with the bulk presence of the higher oxidation state molybdenum oxide sites.

\subsection{Alcohol distribution}

The results of alcohol distribution in the temperature range of $250-325^{\circ} \mathrm{C}$ on Mo-N/AC catalysts are pre- sented in Figure 4. It is obvious from the results that methanol was the major alcohol produced on all the studied Mo-N/AC catalysts at temperatures up to $300^{\circ} \mathrm{C}$. Further, methanol selectivity decreased with increase in the reaction temperature. At the same time, improved $\mathrm{C}_{2}^{+}$alcohol selectivity indicates that methanol homologation/ $\mathrm{CO}$ insertion to $-\mathrm{C}_{\mathrm{x}} \mathrm{H}_{\mathrm{y}}$ intermediate to chain propagation, was the additional reaction route leading to $\mathrm{C}_{2}^{+}$alcohol formation.

This phenomenon was intensified at $325^{\circ} \mathrm{C}$ particularly on the catalysts having 10 and $15 \mathrm{wt} \%$ Mo. Interestingly, propanol was the second highest selective compound in the alcohol distribution after methanol in all the cases, except on $10 \mathrm{Mo}-\mathrm{N} / \mathrm{AC}$ at $325^{\circ} \mathrm{C}$. Further, selectivity of propanol (39\%) was greater than that of methanol (34\%) and ethanol (13.5\%) on10Mo$\mathrm{N} / \mathrm{AC}$ at $325^{\circ} \mathrm{C}$. Butanol selectivity for all the cases was less than $3 \%$. It is obvious from the alcohol distribution results that Mo-N/AC catalyst has some unique characteristics for showing high selectivity to $\mathrm{C}_{3}$ alcohol. Getting high selectivity to propanol is very interesting and a new phenomenon, as according to Anderson-Schulz-Flory (ASF) distribution, the chain propagation should continue to high selectivity to the bulky end product, i.e., butanol. Somehow, the chain propagation was ceased after formation of $\mathrm{C}_{3}$ alcohol on Mo-N/AC catalysts. Further study is under progress to assess the effect of alkali metals on the catalyst.

The selectivity $\left(\mathrm{CO}_{2}\right.$ free $)$ of ethanol and propanol in alcohol products together at $325^{\circ} \mathrm{C}$ decreased in the following order: $10 \mathrm{Mo}-\mathrm{N} / \mathrm{AC}(52.5 \%)>15 \mathrm{Mo}-\mathrm{N} / \mathrm{AC}$ $(43.5 \%)>5 \mathrm{Mo}-\mathrm{N} / \mathrm{AC}(33 \%)$. The greater $\mathrm{C}_{2}^{+}$alcohol selectivity on $10 \mathrm{Mo}-\mathrm{N} / \mathrm{AC}$ was associated with higher adsorption capacity for $\mathrm{CO}$ and $\mathrm{H}_{2}$. Miura et al., ${ }^{28}$ also reported that $\mathrm{CO}$ hydrogenation selectivity depends on $\mathrm{CO}$ chemisorption capacity of bulk $\mathrm{MoO}_{3}$ and molybdophosphoric acids. The other oxygenates selectivity also increased with increase in the reaction temperature on these catalysts.

\subsection{Influence of support properties and Mo loading on the oxygenates formation}

In the present study, the AC contains small portion of surface acidic groups as evidenced by XPS/FTIR analysis. It is well-known that acidic supports such as $\mathrm{Al}_{2} \mathrm{O}_{3}$ and $\mathrm{ZrO}_{2}$ suppress the formation of alcohols and increase the hydrocarbon formation on pre-reduced Mo catalysts. The present DARCO AC contains mostly $s p^{3}$ hybridized carbon atoms and C-O (ethers and phenol) functional groups with mesopores, which provide suitable interaction conditions between Mo and AC sur- 


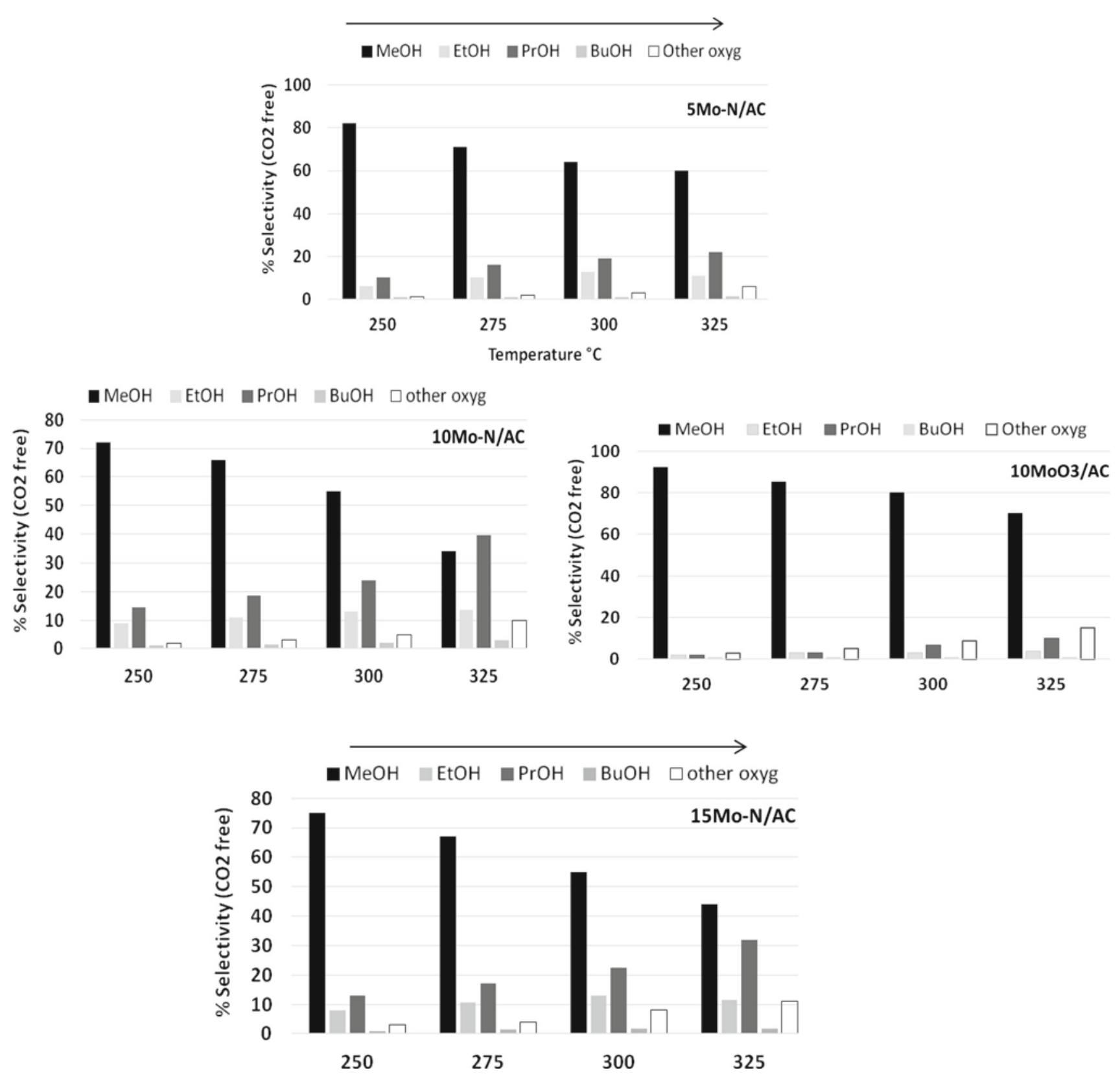

Figure 4. Alcohol distribution on Mo/AC catalysts in the temperature range of $250-325^{\circ} \mathrm{C}, 7 \mathrm{MPa}$ and GHSV $12000 / \mathrm{h}$ (reactor volume $0.5 \mathrm{~mL}$ ).

face. FTIR analysis of the spent AC and Mo-N/AC catalysts are presented in Figure S7 (a) (Supplementary Information). The sample exhibited identical bands as fresh catalysts in the finger print region of 400 $1500 \mathrm{~cm}^{-1}$ and in the functional group region (4000$1500 \mathrm{~cm}^{-1}$ ). In addition, new bands appeared at 2850 and $2920 \mathrm{~cm}^{-1}$ for all the spent catalysts. They are attributed to $\mathrm{C}-\mathrm{H}$ vibration of hydrocarbons present on the surface of $\mathrm{Mo} / \mathrm{AC}$ catalysts. The results of XPS measurements of the spent 10Mo-N/AC catalyst shows (Figure S7 (b)) the relatively increased C-O functional group of $\mathrm{AC}$ over its fresh counterpart, which reveals that Mo mobilization from C-O-Mo complex to the mesopores of $\mathrm{AC}$ during the $\mathrm{CO}$ hydrogenation. It is obvious from the spent catalyst analysis that the employed DARCO AC is stable at $325^{\circ} \mathrm{C}$ and 7 MPa.

\section{Conclusions}

Mo-N/AC catalyst showed interesting product selectivity, especially to alcohols $\left(\mathrm{C}_{1}-\mathrm{C}_{3}\right)$, for $\mathrm{CO}$ hydrogenation reaction. This is associated with $\mathrm{Mo}^{\delta+}$ sites present on $\mathrm{AC}$ as revealed by CO-TPD studies. Among the MoN/AC catalysts, 10Mo-N/AC was found to be the most promising catalyst for $\mathrm{CO}$ hydrogenation to hydrocar- 
bons and oxygenates due to high affinity for molecular $\mathrm{CO}$ adsorption and insertion into $-\mathrm{C}_{\mathrm{x}} \mathrm{H}_{\mathrm{y}}$. High selectivity to propanol, $39 \%$ over $34 \%$ for methanol, in alcohol distribution highlights the unique catalytic behavior of $10 \mathrm{Mo}-\mathrm{N} / \mathrm{AC}$ for $\mathrm{CO}$ hydrogenation reaction at $325^{\circ} \mathrm{C}$.

The $10 \mathrm{MoO}_{3} / \mathrm{AC}$ catalyst, with no treatment of ammonia, showed only $4 \%$ of $\mathrm{CO}$ conversion and $96 \%$ hydrocarbon selectivity. These results suggest that improved oxygenates selectivity is associated with ammonia treatment which led to $\mathrm{Mo}^{\delta+}$ sites. Our group is performing experiments to assess the effect of alkali metal on 10Mo-N/AC catalyst for $\mathrm{CO}$ hydrogenation reaction.

\section{Supplementary Information (SI)}

The XRD, FTIR, XPS, TEM, HR-TEM of fresh catalyst, Figures S1-S6 and FTIR, XPS of spent catalyst, Figures S7 are presented in Supplementary Information, available at www. ias.ac.in/chemsci.

\section{Acknowledgements}

This project was funded by the National Plan for Science, Technology and Innovation (MAARIFAH)-King Abdulaziz City for Science and Technology, the Kingdom of Saudi Arabia, (Award Number 12-PET2720-03). The authors acknowledge technical support with thanks Science and Technology Unit, King Abdulaziz University.

\section{References}

1. Zaman S and Smith K J 2012 A Review of Molybdenum Catalysts for Synthesis Gas Conversion to Alcohols: Catalysts, Mechanisms and Kinetics Catal. Rev. Sci. Eng. 54 41

2. Paris R S, Montes V, Boutonnet $\mathrm{M}$ and Jaras $\mathrm{S}$ 2015 Higher Alcohol Synthesis over Nickel-Modified Alkali-doped Molybdenum Sulfide Catalysts Prepared by Conventional Coprecipitation and Coprecipitation in Microemulsions Catal. Today 258294

3. Iranmahboob J, Toghiani H and Hill D 2003 Dispersion of Alkali on the Surface of Co-MoS $/$ /Clay Catalyst: A Comparison of $\mathrm{K}$ and Cs as a Promoter for Synthesis of Alcohol Appl. Catal. A: Gen. 247207

4. Liakakou E T and Heracleous E 2016 Transition Metal Promoted $\mathrm{K} / \mathrm{Mo}_{2} \mathrm{C}$ as Efficient Catalysts for $\mathrm{CO}$ Hydrogenation to Higher Alcohols Catal. Sci Technol. 61106

5. Lee J H, Hariprasad Reddy K, Jung J S and Yang E -H 2014 Role of Support on Higher Alcohol Synthesis from Syngas Appl. Catal. A: Gen. $\mathbf{4 8 0} 128$

6. Surisetty V R, Dalai A K and Kozinski J 2011 Alcohols as Alternative Fuels: An Overview Appl. Catal. A: Gen. 4041

7. Duchet J C, Vanoers E M, Debeer V H J and Prins R 1983 Carbon-supported Sulfide Catalysts J. Catal. 80386

8. Gang L, Chengfang Z, Yanqing C, Zhibin Z, Yianhui N, Linjun C and Fong Y 1997 Synthesis of Mixed Alcohols from $\mathrm{CO}_{2}$ Contained Syngas on Supported Molybdenum Sulfide Catalysts Appl. Catal. A 150243

9. Iranmahboob J and Hill D 2002 Alcohol Synthesis from Syngas over $\mathrm{K}_{2} \mathrm{CO}_{3} / \mathrm{CoS} / \mathrm{MoS}_{2}$ on Activated Carbon Catal. Lett. 7849

10. Li Z R, Fu Y L, Jiang M, Hu T D, Liu T and Xie Y N 2001 Active Carbon Supported Mo-K Catalysts Used for Alcohol Synthesis J. Catal. 199155

11. Ma X, Lin G and Zhang H 2006 Co-Mo-K Sulfide-Based Catalyst Promoted by Multiwalled Carbon Nanotubes for Higher Alcohol Synthesis from Syngas Chin. J. Catal. 271019

12. Surisetty V R, Dalai A K and Kozinski J 2010 AlkaliPromoted Trimetallic Co-Rh-Mo Sulfide Catalysts for Higher Alcohols Synthesis from Synthesis Gas: Comparison of MWCNT and Activated Carbon Supports Ind. Eng. Chem. Res. 496956

13. Liakakou E T, Heracleous E, Triantafyllids K S and Lemonidou A A 2015 K-promoted NiMo Catalysts Supported on Activated Carbon for the Hydrogenation Reaction of CO to Higher Alcohols: Effect of Support and Active Metal Appl. Catal. B: Environ. 165296

14. Ma C-H, Li H-Y and Lin G-D 2010 MWCNT-Supported Ni-Mo-K Catalyst for Higher Alcohol Synthesis from Syngas Catal. Lett. 137171

15. Wang J-J, Xie J-R, Huang Y-H, Chen B-H, Lin G-D and Zhang H-B 2013 An Efficient Ni-Mo-K Sulfide Catalyst Doped with CNTs for Conversion of Syngas to Ethanol and Higher Alcohols Appl. Catal. A: Gen. 46844

16. Shao Y, Xu Z, Wan H, Chen H, Zheng S and Zhu D 2011 Enhanced Liquid Phase Catalytic Hydrodechlorination of 2,4-dichlorophenol over Mesoporous Carbon Supported Pd Catalysts Catal. Commun. 121405

17. Zhang Y, Wang A and Zhang T $2010 \mathrm{~A}$ New 3D Mesoporous Carbon Replicated from Commercial Silica as a Catalyst Support for Direct Conversion of Cellulose into Ethylene Glycol Chem. Commun. 46862

18. Hussain M and Ihm S-K 2009 Synthesis, Characterization, and Hydrodesulfurization Activity of New Mesoporous Carbon Supported Transition Metal Sulfide Catalysts Ind. Eng. Chem. Res. 48698

19. Strzemiecka B, Voelkel A, Donate-Robles J and MartinMartinez J M 2014 Assessment of the Surface Chemistry of Carbon Blacks by TGA-MS, XPS and Inverse Gas Chromatography Using Statistical Chemometric Analysis Appl. Surf. Sci. 316315

20. Sing K S W, Everett D H, Haul R A W, Moscou L, Pierotti R A, Rouquerol J and Siemieniewska T 1985 Reporting Physorption Data for Gas/Solid Systems with Special Reference to the Determination of Surface Area and Porosity Pure Appl. Chem. 57603

21. Ghampson I T, Sepulveda C, Garcia R, Radovic L R, Fierro J L G, DeSisto $\mathrm{W} J$ and Escalona N 2012 Hydrodeoxygenation of Guaiacol over Carbonsupported Molybdenum nitride Catalysts: Effects of Nitriding Methods and Support Properties Appl. Catal. A: Gen. 439-440 111

22. Sepulveda C, Leiva K, Garcia R, Radovic L R, Ghampson I T, DeSisto W J, Fierro J L G and Escalona N 2011 Hydrodeoxygenation of 2-methoxyphenol over $\mathrm{Mo}_{2} \mathrm{~N}$ Catalysts Supported on Activated Carbons Catal. Today 172232 
23. de la Puente G, Centeno A, Gil A and Grange P 1998 Interactions between Molybdenum and Activated Carbons on the Preparation of Activated Carbon-Supported Molybdenum Catalysts J. Colloid Interface Sci. 202155

24. Shaheen W M and Selim M M 2002 Thermal Behaviour of Pure and Binary Basic Nickel Carbonate and Ammonium Molybdate Systems Mater. Lett. 52272

25. Vissers J P R, Bouwens S M A M, de Beer V H J and Prins R 1987 Carbon Black-supported Molybdenum Sulfide Catalysts Carbon 25485

26. Tien $\mathrm{H}-\mathrm{W}$, Huang $\mathrm{Y}-\mathrm{L}$, Yang $\mathrm{S}-\mathrm{Y}$, Hsiao $\mathrm{S}-\mathrm{T}$, Wang J -U, Ma C -C M 2011 Graphene Nanosheets Deposited on Polyurethane Films by Self-assembly for Preparing Transparent, Conductive Films J. Mater. Chem. 2114876

27. Lee J S, Lee K H and Lee J Y 1992 Selective Chemisorption of Carbon Monoxide and Hydrogen over Supported Molybdenum Carbide Catalysts J. Phys. Chem. 96362

28. Miura H, Osawa M, Sugiyuma K and Matsuda T 1986 The Adsorption of $\mathrm{CO}$ and Hydrogen on Reduced Molybdenum Catalysts Used for CO Hydrogenation $J$. Catal. 101178
29. Zaman S F, Pasupulety N, Al-Zahrani A A, Daous M A, Al-Shahrani S S, Driss H, Petrov L A and Smith K J 2017 Carbon Monoxide Hydrogenation on Potassium Promoted $\mathrm{Mo}_{2} \mathrm{~N}$ Catalysts Applied Catalysis A: Gen. $\mathbf{5 3 2} 133$

30. Kumar P, Mungse H P, Cordier S, Boukherroub R, Khatri O P and Jain S L 2015 Hexamolybdenum Clusters Supported on Graphene Oxide: Visible-light Induced Photocatalytic Reduction of Carbon Dioxide into Methanol Carbon 9491

31. Li X, Feng L, Zhang L, Dadyburjour D B and Kugler E D 2003 Alcohol Synthesis over Pre-Reduced Activated Carbon-Supported Molybdenum-Based Catalysts Molecules 813

32. Saito M and Anderson R B 1980 The Activity of Several Molybdenum Compounds for the Methanation of $\mathrm{CO} J$. Catal. 63438 